\title{
Attitudes to tracing and notifying contacts of people with HIV infection
}

\author{
R A Keenlyside, A S Hawkins, A M Johnson, M W Adler
}

In the early years of the HIV/AIDS epidemic the notion of combating the disease by the traditional approach for controlling other sexually transmitted diseases-that is, tracing contacts and notifying partners-met with heated debate.

Though most health care workers agreed that all people infected with HIV should inform their sexual partners and those with whom they shared needles (that is, patient referral), many believed health care providers should not do the informing (that is, provider referral). Concerns were loss of confidentiality, the potential for stigmatisation of infected people, and the fear of alienating those who might otherwise have come forward for testing balanced against the rights of exposed subjects to be informed of their risk and identified..$^{1-6}$

At that early stage the natural course of the infection was poorly understood, no treatments were available, and it had not been established that personal counselling for high risk contacts resulted in sustained change in behaviour. Opponents of notification of partners believed that national education campaigns were adequate; proponents believed that these messages were not necessarily reaching people who did not suspect they were at risk.

But the situation has evolved. In the United States, Canada, Belgium, and Scandinavia notification of partners has gained favour as a legitimate approach to managing HIV infection as a result of evidence of the changing epidemiology of the infection and studies showing the beneficial effects of early antiviral treatment and prophylaxis for opportunistic infections. ${ }^{7-11}$

In the United Kingdom medical staff in genitourinary medicine clinics have the major responsibility for managing people with early HIV infection. The only official guidelines for tracing contacts are those for the common sexually transmitted diseases, which were published in 1980, before the HIV epidemic emerged. ${ }^{12}$

Therefore, to examine attitudes and practices regarding the notification of partners in the United Kingdom we surveyed consultant physicians and health advisers in genitourinary medicine clinics.

\section{Subjects and methods}

In October 1991 we sent a questionnaire to 146 consultant genitourinary physicians who were readily identified as working in $204(95 \%)$ of the 214 genitourinary medicine clinics known to the Department of Health; $39(27 \%)$ had appointments at two or more clinics. We sent a reminder six weeks later to $52(35 \%)$ who failed to respond; completed questionnaires were eventually received from $105(72 \%)$ consultants.

Health advisers were more difficult to identify as a group. Initially, we sent the questionnaire to 139 health advisers identified by the Society of Health Advisers in Sexually Transmitted Diseases and the Health Advisers Special Interest Group and a reminder six weeks later to the $72(51 \%)$ who failed to respond; 22 replied. However, as so many health advisers were untraceable, a further 110 questionnaires were distributed to health advisers identified by telephoning 67 clinics, including all 23 London clinics: 52 health advisers replied, giving an overall response rate of $57 \%(141 / 249)$

The questionnaire had three parts. The firs requested demographic information, details of work experience, and the number of health advisers working in each clinic. Other questions inquired about training for dealing with sexually transmitted diseases and HIV counselling, access to guidelines; policies for offering HIV antibody tests, counselling practices before and after testing, and the extent to which health adviser were directly involved in referral of partners.

In the second part participants were asked if they agreed with statements about the effectiveness of partner notification programmes. Opinions were canvassed on a five point Likert-type scale (strongly agree, agree, uncertain, disagree, strongly disagree) which was subsequently converted to a three point scale because the response frequencies of the extreme categories were small. There was a low non-response rate for these items (1-4\% among consultants and $0-5 \%$ among health advisers)

Finally, respondents were asked for their recommendations for counselling contacts of people in a series of hypothetical situations of high risk HIV exposure. The allowable responses were agree, uncertain, and disagree. The non-response rates for these questions were not trivial, particularly among the health advisers (7-12\%), and non-response was included as a fourth category for the analyses.

As health advisers provide most of the counselling and the physicians are responsible for clinic policies we were interested to know whether their opinions differed. Also, because the four Thames regions have reported three quarters of HIV/AIDS cases in England and Wales, we compared the opinions and practices of staff in these high prevalence areas with those of staff in the rest of the United Kingdom. ${ }^{13}$

The analyses reported in table III are based on the underlying $2 \times 3$ and $2 \times 4$ contingency tables respectively, with $\chi^{2}$ tests of significance to investigate any 
differences of opinion between the two groups of respondents.

\section{Results}

The overall response to the questionnaire was $63 \%$ (246/395) and was significantly lower among health advisers than consultant physicians (57\% (141/249) $v$ $72 \%(105 / 146) ; \mathrm{p}<0.002)$ because of the significantly lower response rate among health advisers in the Thames regions compared with elsewhere $(44 \%$ $(36 / 81)$ v 63\% (105/168); $\mathrm{p}<0 \cdot 01)$. The rates were similar in physicians within and outside the Thames regions $(75 \%(27 / 36 v 71 \%(78 / 110))$

Eighty one $(77 \%)$ of the 105 physicians were male, and $98(93 \%)$ identified themselves as "clinic directors." They worked in $146(72 \%)$ of the 204 clinics surveyed and identified 206 health advisers as colleagues (about two each). In contrast, $129(91 \%)$ of the 141 health advisers were female. Most $(102,73 \%)$ had nursing or health visitor qualifications, $12(8 \%)$ were trained principally in counselling and social work, and $27(19 \%)$ had "non-medical" qualifications. Health advisers in the Thames regions and those outside had similar qualifications. Physicians and health advisers differed in their work histories: $63(60 \%)$ physicians had worked in genitourinary medicine for more than 10 years compared with only $27(19 \%)$ health advisers $(\mathrm{p}<0.00001)$, and they had been in their present posts for longer (mean $9 \cdot 3 v 4 \cdot 3$ years).

HIV antibody tests were available in almost all clinics and only a few staff would never offer the test to clients (table I). Physicians were significantly more likely than health advisers to offer the test to selected clients, and especially those with high risk behaviour. Written informed consent of clients before testing was required in $20-32 \%$ of clinics. Almost all health advisers $(136,98 \%)$ and physicians $(103,99 \%)$ said they had given pretest counselling (data not shown), but proportionately more health advisers had received training in counselling than physicians.

Sixty three per cent of all respondents had available written guidelines for counselling HIV infected patients, usually drawn up by clinic staff, only $24 \%$ of which contained recommendations for notifying partners (data not shown)

TABLE I - Number (percentage) of affirmative answers relating to counselling and testing for HIV and policy for notifying partners

\begin{tabular}{|c|c|c|c|}
\hline & $\begin{array}{l}\text { Consultant } \\
\text { physicians } \\
(\mathrm{n}=105)\end{array}$ & $\begin{array}{c}\text { Health } \\
\text { advisers } \\
(\mathrm{n}=141)\end{array}$ & p Value \\
\hline \multicolumn{4}{|l|}{ Counselling and offering HIV test } \\
\hline Is HIV antibody testing available in your clinic? & $104(99)$ & $139(99)$ & \\
\hline \multicolumn{4}{|l|}{ Which of the following approaches do you personally advocate? } \\
\hline Offering the test to all clients & $46(44)$ & $83(59)$ & $<0.05$ \\
\hline Offering the test to selected clients & $55(52)$ & $38(27)$ & $<0.0001$ \\
\hline Never offering the test to clients & $2(2)$ & $8(6)$ & $>0 \cdot 1$ \\
\hline Is written informed consent required? & $22(21)$ & $44(32)$ & $>0.05$ \\
\hline Have you had HIV counselling training? & $67(64)$ & $113(81)$ & 0.004 \\
\hline \multicolumn{4}{|l|}{ Policies for notifying partners } \\
\hline $\begin{array}{l}\text { Is it important to identify the contacts of HIV infected patients in order to provide them with counselling and } \\
\text { follow up? }\end{array}$ & $97(92)$ & $81(57)$ & $<0.0001$ \\
\hline $\begin{array}{l}\text { Do you routinely discuss contact tracing/patient notification during pretest counselling interviews with } \\
\text { clients? }\end{array}$ & $58(55)$ & $91(67)$ & $>0.05$ \\
\hline Do you encourage patients with HIV infection to refer their contacts during post-test counselling interviews? & $103(98)$ & $102(81)$ & $<0.0001$ \\
\hline $\begin{array}{l}\text { Do you offer your services (or services of your staff) for getting in touch with contacts of HIV infected persons } \\
\text { if the client is reluctant to do so? }\end{array}$ & $59(58)$ & $71(55)$ & $0 \cdot 1$ \\
\hline
\end{tabular}

TABLE II - Attitudes among consultant physicians and health advisers to partner notification programmes for HIV infection

\begin{tabular}{|c|c|c|c|c|}
\hline \multirow[b]{2}{*}{ Statement } & \multicolumn{3}{|c|}{ Opinion $(\%(\mathrm{No}))$} & \multirow[b]{2}{*}{ p Value } \\
\hline & Agree & Uncertain & Disagree & \\
\hline \multicolumn{5}{|c|}{ Value of intervention } \\
\hline \multicolumn{5}{|c|}{ (1) Early medical intervention can be beneficial for HIV infected persons with no symptoms } \\
\hline Physicians $(n=104)$ & $64(67)$ & $24(25)$ & $12(12)$ & \multirow{2}{*}{0.05} \\
\hline Health advisers $(n=139)$ & $73(101)$ & $21(29)$ & $6(9)$ & \\
\hline \multicolumn{5}{|c|}{ (2) People are adequately informed by media campaigns about their risk and would not benefit from personal counselling } \\
\hline Physicians $(n=103)$ & $6(6 / 103)$ & $3(3 / 103)$ & $91(94)$ & \multirow{2}{*}{$0 \cdot 6$} \\
\hline Health advisers $(n=138)$ & $4(6)$ & $5(7)$ & $91(125)$ & \\
\hline \multicolumn{5}{|c|}{ (3) Informing high risk contacts of their exposure is of no value in controlling the epidemic of HIV and AIDS } \\
\hline Physicians $(n=104)$ & $4(4)$ & $7(7)$ & $89(93)$ & \multirow{2}{*}{$<0 \cdot 001$} \\
\hline \multirow[t]{2}{*}{ Health advisers $(n=139)$} & $12(16)$ & $22(31)$ & $66(92)$ & \\
\hline & & & & \\
\hline \multicolumn{5}{|c|}{ (4) Publicised policies for contact tracing/patient notification by clinic personnel would deter potential clients from seeking the test } \\
\hline Physicians $(n=101)$ & $52(53)$ & $28(28)$ & $20(20)$ & \multirow{2}{*}{$<0 \cdot 01$} \\
\hline Health advisers $(n=140)$ & $71(100)$ & $19(26)$ & $10(14)$ & \\
\hline \multicolumn{5}{|c|}{ (5) Contact tracing for HIV infection by clinic personnel undermines the confidential nature of the professional client relationship } \\
\hline Physicians $(\mathbf{n}=101)$ & $31(31)$ & $11(11)$ & $58(59)$ & \multirow{2}{*}{$0 \cdot 01$} \\
\hline Health advisers $(n=139)$ & $45(63)$ & $17(24)$ & $37(52)$ & \\
\hline \multicolumn{5}{|c|}{ (6) People contacted and told of their HIV exposure would be made unnecessarily anxious } \\
\hline Physicians $(n=103)$ & $19(20)$ & $23(24)$ & $57(59)$ & \multirow{2}{*}{0.01} \\
\hline \multirow[t]{2}{*}{ Health advisers $(n=134)$} & $37(49)$ & $26(35)$ & $37(50)$ & \\
\hline \multirow{2}{*}{\multicolumn{5}{|c|}{ (7) Contacts have a right to know of their exposure to HIV infection }} \\
\hline & & & & \multirow{3}{*}{$>0 \cdot 05$} \\
\hline Physicians $(n=103)$ & $73(75)$ & $19(20)$ & $7(8)$ & \\
\hline Health advisers $(n=140)$ & $60(84)$ & $25(35)$ & $15(21)$ & \\
\hline \multicolumn{5}{|c|}{ (8) Contacts have a right not to know of their HIV exposure } \\
\hline Physicians $(n=105)$ & $29(30)$ & $18(19)$ & $53(56)$ & \multirow{2}{*}{$<0 \cdot 01$} \\
\hline Health advisers $(n=141)$ & $43(61)$ & $26(36)$ & $31(44)$ & \\
\hline \multicolumn{5}{|c|}{ (9) It is the sole responsibility of the patient to inform and refer his or her contacts for follow up } \\
\hline Physicians $(n=102)$ & $28(29)$ & $18(18)$ & $54(55)$ & \multirow{2}{*}{$>0 \cdot 05$} \\
\hline Health advisers $(n=137)$ & $37(51)$ & $23(32)$ & $39(54)$ & \\
\hline \multirow{2}{*}{\multicolumn{4}{|c|}{$\begin{array}{l}\text { Are resources adequate? } \\
\text { (10) Limited resources for AIDS prevention would be better spent on public education campaigns than on individuals at risk }\end{array}$}} & \\
\hline $\begin{array}{l}\text { (10) Limited resources for A } \\
\text { Physicians }(\mathrm{n}=103)\end{array}$ & & & & \multirow[b]{2}{*}{$<0 \cdot 05$} \\
\hline Health advisers $(n=133)$ & $32(42)$ & $25(33)$ & $44(58)$ & \\
\hline \multicolumn{5}{|c|}{$\begin{array}{l}\text { (11) Existing services cannot meet the demand for counselling and support that would be generated by increased partner referral } \\
\text { (1) }\end{array}$} \\
\hline Physicians $(n=104)$ & $33(34)$ & $21(22)$ & $46(48)$ & \multirow{2}{*}{$<0 \cdot 001$} \\
\hline Health advisers $(n=138)$ & $60(83)$ & $12(17)$ & $28(38)$ & \\
\hline
\end{tabular}

«Values $<0.05$ indicate a significant association between the professionl roles of the respondents and their expressed opinions. 
Opinion (\% (No))

Agree Uncertain

Disagree

Sexual contacts of an infected homosexual man who were identified and contactable, who had unprotected exposure during previous year

Physicians

Health advisers

Traceable casual female contacts of an infected bisexual man, who had unprotected exposure during the past year and were unaware of their risk

Physicians

Health advisers

Identified male sexual contacts of a woman with a diagnosis of AIDS over the past year

Physicians

Health advisers

Identified male sexual contacts of a woman with a diagnosis of AIDS over the past 5 years

Physicians

Health advisers

Wife of an infected bisexual man who has had unprotected exposure and is unaware of her husband's bisexuality. The husband does not want to divulge his bisexuality

Physicians

Health advisers

Identified and traceable contacts of an infected intravenous drug user who have shared needles with the patient over the past year past year
Physicians

Health advisers

Identified and traceable contacts of an infected intravenous drug user who had unprotected sexual exposure and are unaware of their exposure over the previous year

Physicians

Physicians

All identified and traceable heterosexual partners of infected persons with haemophilia who are unaware of their exposure over the previous year Physicians

Health advisers

All identified and traceable heterosexual partners of individuals infected through sexual exposure in Africa-over the previous year

Physicians

Health advisers

\begin{tabular}{|c|c|c|c|c|}
\hline $\begin{array}{l}83(87) \\
57(81)\end{array}$ & $\begin{array}{l}10(10) \\
21(30)\end{array}$ & $\begin{array}{c}5(5) \\
13(19)\end{array}$ & $\begin{array}{c}3(3) \\
11(18)\end{array}$ & $<0.001$ \\
\hline $\begin{array}{l}82(86) \\
56(79)\end{array}$ & $\begin{array}{l}10(11) \\
21(30)\end{array}$ & $\begin{array}{c}5(5) \\
14(20)\end{array}$ & $\begin{array}{l}3(3) \\
9(12)\end{array}$ & $<0.001$ \\
\hline $\begin{array}{l}77(81) \\
57(80)\end{array}$ & $\begin{array}{l}10(11) \\
21(29)\end{array}$ & $\begin{array}{c}7(7) \\
12(17)\end{array}$ & $\begin{array}{c}6(6) \\
11(15)\end{array}$ & $0 \cdot 1$ \\
\hline $\begin{array}{l}49(51) \\
43(61)\end{array}$ & $\begin{array}{l}35(37) \\
30(42)\end{array}$ & $\begin{array}{l}11(12) \\
15(21)\end{array}$ & $\begin{array}{c}4(4) \\
12(17)\end{array}$ & $0 \cdot 1$ \\
\hline $\begin{array}{l}72(76) \\
43(61)\end{array}$ & $\begin{array}{l}20(21) \\
31(44)\end{array}$ & $\begin{array}{c}4(4) \\
15(21)\end{array}$ & $\begin{array}{c}4(4) \\
11(15)\end{array}$ & $<0.001$ \\
\hline $\begin{array}{l}85(89) \\
55(78)\end{array}$ & $\begin{array}{c}9(9) \\
22(31)\end{array}$ & $\begin{array}{c}4(4) \\
13(18)\end{array}$ & $\begin{array}{c}3(3) \\
10(14)\end{array}$ & $<0.001$ \\
\hline $\begin{array}{l}83(87) \\
53(75)\end{array}$ & $\begin{array}{l}11(12) \\
24(34)\end{array}$ & $\begin{array}{c}3(3) \\
13(18)\end{array}$ & $\begin{array}{c}3(3) \\
10(14)\end{array}$ & $<0.001$ \\
\hline $\begin{array}{l}77(81) \\
53(75)\end{array}$ & $\begin{array}{l}15(16) \\
23(33)\end{array}$ & $\begin{array}{c}5(5) \\
13(18)\end{array}$ & $\begin{array}{c}3(3) \\
11(15)\end{array}$ & $<0.001$ \\
\hline $\begin{array}{l}79(83) \\
55(77)\end{array}$ & $\begin{array}{l}12(13) \\
21(30)\end{array}$ & $\begin{array}{c}5(6) \\
13(18)\end{array}$ & $\begin{array}{c}3(3) \\
11(16)\end{array}$ & $<0.0$ \\
\hline
\end{tabular}

Asked whether it was important to identify the high risk contacts of HIV infected patients to provide them with counselling and follow up, significantly fewer health advisers than physicians agreed $(81 / 141(57 \%) v$ 97/105 (92\%), $\mathrm{p}<0.0001$; table I). In the Thames regions, only $14 / 36(39 \%)$ of health advisers agreed compared with 67/105 (64\%) elsewhere. Among physicians, over $97 / 105(92 \%)$ agreed in both areas.

When counselling patients before testing, about half of the physicians and two thirds of the health advisers discussed partner notification routinely and there were no differences between Thames and outside regions. A high percentage in both groups $(98 \%$ and $81 \%)$ also encouraged HIV infected patients to inform their contacts after testing but far fewer (55\% and 58\%) offered their services for referring contacts if clients were reluctant to do so themselves. Again, significantly fewer staff in the Thames regions than elsewhere $(11 / 25(44 \%)$ of physicians and $10 / 34(29 \%)$ of health advisers compared with almost two thirds (109/172, $63 \%$ ) in both groups elsewhere) would offer these services $(p=0 \cdot 0002)$.

Opinions about the probable effectiveness of notification of partners varied. Most physicians and health advisers agreed that early intervention could benefit persons with asymptomatic HIV infection. They disagreed, however, with the statement that people are generally well enough informed about the risks of HIV infection and therefore would not benefit from extra counselling. Health advisers were significantly more likely than physicians to agree that informing contacts was of no value in controlling the epidemic and would deter clinic attendance, threaten confidentiality, undermine the professional-client relationship, and make informed contacts unnecessarily anxious (table II).

Physicians seemed more likely than health advisers to agree that contacts have a right to know of their exposure, although this was not significant. Health advisers were more likely to agree that contacts had a right not to know, but they were also more undecided about this (questions 7,8 ). Opinions were divided about the responsibility of patients to inform their contacts (question 9). However, a higher percentage of health advisers in the Thames regions than elsewhere $(21 / 36(58 \%) v 30 / 105(29 \%))$ believed that only patients should do this. Health advisers were also significantly more likely than physicians to agree that existing services could not meet an increased demand for partner referral (questions 10, 11).

When presented with several scenarios of HIV exposure a significantly higher proportion of physicians than health advisers in each case agreed that the contacts should be informed, but in most cases a highe proportion of health advisers were uncertain in their replies (table III). In the Thames regions up to $45 \%$ fewer health advisers than physicians agreed; indeed between $19 \%$ and $25 \%$ (seven and nine) of the 36 health advisers in the Thames regions and between $4 \%$ and $8 \%$ of the 105 in the other regions refused to respond to these questions.

\section{Discussion}

Counselling and testing for HIV infection is widely available in genitourinary medicine clinics in the United Kingdom, and staff generally agree that notification of partners is important, although they are reluctant to become directly involved. The health advisers, whose traditional role has been to promote referral of partners, are particularly sceptical, especially those in the Thames regions. Elsewhere, in low prevalence areas, staff seem to favour a more traditional approach, in which health advisers are directly involved in notification.

The differences of opinion we observed between the physicians or supervisors and the counsellors, although striking, may not be typical of the profession and should be interpreted with caution. The sample of physicians was small and made up almost entirely of experienced clinic directors who were perhaps more likely to view partner notification as a "disease control" measure. On the other hand, although we questioned a larger sample of health advisers, responses came mainly from those with nursing and health visitor training. The views of health advisers with other backgrounds, especially in counselling, may be under- 
represented. This may be particularly true in the Thames regions, which have the highest concentrations of counsellors and people with HIV or AIDS but the lowest response rates in the study. The regional differences in attitudes and practices are probably a reflection of clinic workloads, the mix of HIV exposure groups among clients, and the resources available for counselling and follow up. Resources may be adequate in low prevalence areas with small numbers of HIV infected clients who have few contacts; but in busy clinics in the south east staff may feel unable to deal with the many mobile and potentially untraceable partners of a large number of clients.

Practices in notifying partners may have changed after the decline of gonorrhoea and infectious syphilis over the past decade. For instance, provider referral is now less common in these infections, and patients are being encouraged to be more involved. ${ }^{1+}$ There are no national surveillance data, however, to confirm this.

\section{PROVIDER REFERRAL PROGRAMMES}

Since the mid-1980s provider referral for the contacts of patients with HIV infection has been increasingly incorporated into sexually transmitted disease programmes world wide. Programmes have been established in Europe, Scandinavia, parts of the United States and Canada, Australia, and countries in Africa and the Caribbean (M L Rekart et al, fourth international conference on AIDS, Stockholm, 1988)..$^{1+17}$ Some programmes emphasise counselling all contacts whereas others focus on those at high risk who are possibly unaware of their exposures-for example, women of childbearing age and those with heterosexual exposure to bisexual men and intravenous drug users. These programmes have been evaluated for their operational performance, cost effectiveness, and cost benefit and for the reactions of medical staff and clients (N Padian $e t a l$, J M Woo et al, J E Kristofferson et al, fourth international conference on AIDS, Stockholm, $1988^{18-21}$; E M Blankenship et al, N Spencer et al, V Arendt et al, fifth international conference on AIDS, Montreal, 1989). The outcomes have also been somewhat controversial. ${ }^{22-24}$ However, as they frequently identify infected persons who might otherwise have been unaware of their risk the main debate has centred around their cost effectiveness.

Partner notification programmes for HIV infection have not been widely adopted in the United Kingdom, most probably because of continuing concerns about client confidentiality, doubts about their cost effectiveness, and operational questions.

Although the physicians and health advisers seemed reluctant to be directly involved in partner notification for HIV infection, there is evidence that patients attending genitourinary medicine clinics are far less opposed to it. In a recent pilot study of the attitudes of 75 clients attending a general genitourinary medicine clinic in London over three quarters of women and half of men felt that notifying partners in HIV infection should be standard practice and were not unduly concerned about its potential impact on themselves or their contacts ( $\mathrm{S}$ Wanigaratne, personal communication).

\section{USEFULNESS OF PARTNER NOTIFICATION}

Internationally and in the United Kingdom AIDS from heterosexual exposure is increasing at a faster rate than that from male homosexual exposure and injecting drug use, a trend especially affecting women and children. ${ }^{25}$ There is therefore an urgent need to re-examine the usefulness of notifying partners in HIV infection, especially in situations in which contacts may be unaware of their exposure and risk.

Because of the apparent confusion surrounding this issue in the United Kingdom we recommend that there should be national guidelines for notifying partners for areas of low and high HIV prevalence, especially for people who may be unaware of their exposure and auditing of the effectiveness of current practices in genitourinary medicine clinics with focused operational research into cost effectiveness and cost benefit of notifying partners. This will involve reviving the alliance between clinicians, policy makers, epidemiologists, and patient advocates to establish well justified policies appropriate for the United Kingdom to develop rational programmes for the prevention of new HIV infections and management of those already infected.

We thank Ms Kay Stratton for her help in carrying out the study, the committees of the Health Advisers Special Interest Group and Society of Health Advisers in Sexually Transmitted Diseases for their support during the planning stages, and the physicians and health advisers who responded to the questionnaire.

1 Miller D, Pinching AJ. HIV tests and counselling: current issues. AIDS 1989;3(supp 1):S187-93.

2 Adler MW, Johnson AM. Contact tracing for HIV infection. BMF 1988;296: $1420-1$.

3 Potterat JJ, Spencer NE, Woodhouse DE, Muth JB. Partner notification in the control of human immunodeficiency virus infection. Am F Public Health $1989 ; 29: 874-5$

4 Gostin L, Curran WJ. Aids screening confidentiality and the duty to warn. Am f Public Health 1987;77:361-5

5 Toomey KE, Cates W. Partner notification for the prevention of HIV infection. AIDS 1989;3(suppl 1):S57-62.

6 Osborn JE. AIDS: politics and science. N Engl $\mathcal{Y}$ Med 1988;318:444-7.

7 Eron JJ, Hirsch MS. New anti-HIV-1 therapies and combinations: current data and prospects. AIDS 1990;4(suppl 1):S193-200.

8 Feinberg J, Mills J. Treatment of opportunistic infections. AIDS 1990; 4(suppl 1):S209-15.

9 Rhame FS, Maki DG. The case for wider use of testing for HIV infection. $N$ Engl f Med 1989;320:1249.

10 Drotman P. Earlier diagnosis of human immunodeficiency virus (HIV) infection and more counselling. Ann Intern Med 1989;110:680-1.

11 Leen CLS, Brettle RP, Bird AG. Benefits of HIV antibody testing in symptom free risk groups. Lancet 1989;ii:512-3.

12 Health Education Council. A handbook on contact tracing in sexually transmitted diseases. London: Health Education Council, 1980

13 Public Health Laboratory Service and Communicable Disease (Scotland) Unit. AIDS/HIV quarterly surveillance report. London: PHLS, $\mathrm{CD}(\mathrm{S}) \mathrm{U}$, 1991. (No 12.)

14 World Health Organisation. Report of the consultation on partner notification for preventing HIV transmission. Geneva: WHO, 1989. (WHO/GPA/ESR/89.2.)

15 Partner notification for preventing human immunodeficiency virus (HIV) infection-Colorado, Idaho, South Carolina, Virginia. MMWR 1988;37: $393-402$.

16 Ramstedt K, Hallhagen G, Ludin B-I, Hakansson C, Johanisson G, Lowhagen $\mathrm{G}-\mathrm{B}$, et al. Contact tracing for human immunodeficiency virus (HIV) infection. Sex Transm Dis 1989;17:37-41.

17 Wykoff R, Heath C, Hollis S, Leonard S, Quiller C, Jones J, et al. Contact tracing to identify human immunodeficiency virus infection in a rural community. FAMA 1988;259:3563-6.

18 Jones JL, Wykoff RF, Hollis SL, Longshore ST, Gamble WB, Gunn RA Partner acceptance of health department notification of HIV exposure South Carolina. FAMA 1990;264:1284-6.

19 Giesecke J, Ramstedt K, Ripa T, Rado G, Scalia-Tomba G, Westrell M Partner notification for HIV in Sweden. Lancet 1990;336:508-9.

20 Sesnan K, Jackson D, Catto I, Machin J, Wright JK. Contact tracing in HIV infection. Venerology 1989;2:75-80.

21 Giesecke J, Ramstedt K, Granath F, Ripa T, Rado G, Westrell M. Efficacy of partner notification for HIV infection. Lancet 1991;338:1096-100.

22 Vernon T, Hoffman R. Contact tracing to control the spread of HIV fAMA $1988 ; 260: 3274-5$

23 Rutherford GW, Woo JM. Contact tracing and the control of human immunodeficiency virus infection. $\mathcal{F} A M A$ 1988;259:3609-10.

24 Cates W, Handsfield H. HIV counselling and testing: does it work? Am 7 Public Health 1988;78:1533-4.

25 Chin J. Current and future dimensions of the HIV/AIDS pandemic in women and children. Lancet 1990;336:221-4.

(Accepted 10 April 1992) 